\title{
New insight into the role of MDMX in MDM2-mediated p53 degradation and anti-cancer drug development
}

\author{
Jing Yang ${ }^{1,2}$ and Yanping Zhang ${ }^{3}$ \\ ${ }^{1}$ Jiangsu Province Key Laboratory of Immunity and Metabolism, Xuzhou Medical University, Xuzhou, Jiangsu, China \\ ${ }^{2}$ Department of Pathogenic Biology and Immunology, Xuzhou Medical University, Xuzhou, Jiangsu, China \\ ${ }^{3}$ Department of Radiation Oncology and Lineberger Comprehensive Cancer Center, School of Medicine, University of North \\ Carolina at Chapel Hill, Chapel Hill, North Carolina, USA \\ Correspondence to: Jing Yang, email: jingyang@xzhmu.edu.cn \\ Yanping Zhang, email: ypzhang@med.unc.edu
}

Keywords: MDMX; MDM2; 553

Received: June 16, $2021 \quad$ Accepted: July 28, $2021 \quad$ Published: August 09, 2021

Copyright: ( 2021 Yang and Zhang. This is an open access article distributed under the terms of the Creative Commons Attribution License (CC BY 3.0), which permits unrestricted use, distribution, and reproduction in any medium, provided the original author and source are credited.

\section{ABSTRACT}

Inactivation of the tumor suppressor p53 has been generally accepted as a hallmark of tumor. MDM2 and MDMX, the two closely related proteins are considered to be critical for negatively regulating p53 activity through inhibitory binding to and post-translational modification of the $\mathrm{p} 53$ protein. We have demonstrated that MDMX facilitates MDM2-mediated p53 ubiquitination and degradation via recruitment of the ubiquitin-conjugating enzyme UbcH5c to the MDM2-MDMX heterooligomers. Here, we discuss our new findings from genetically engineered mouse models and a potential therapeutic strategy.

\section{INTRODUCTION}

The p53 stress response is an important regulator of cellular homeostasis, responding to a variety of stressors and eliciting hallmark effects on cell proliferation, apoptosis, and senescence [1]. As such, p53 plays an essential role in regulating the balance between cellular growth, proliferation, and destruction. Disturbance of this balance through p53 mutations leads to a wide variety of cancers as well as many other diseases [2]. Due to the high rate of p53 mutation, deletion, and misregulation in human cancers, in theory $\mathrm{p} 53$ regulated signaling pathways should be attractive drug targets. However, effective therapeutics utilizing such pathways has yet to find their ways into the clinic [3-6]. The lack of a complete understanding of p53 regulation, particularly its in vivo regulation, is at least in part to blame. Most p53-activation compounds developed to date offer relatively specific MDM2 inhibition by targeting the p53-binding domain on MDM2, such as nutlin [7]. However, their efficacy in patients has been disappointing, which can be attributed to multiple factors and the most prominent one is the on-target toxicity caused by exaggerated activation of p53 [8]. However, even if side effects could be minimized, it is possible that MDM2 inhibition alone could be ineffective because inhibitors that target only MDM2 and not MDMX are ineffective against cancer cells that overexpress MDMX. Thus, although potent MDM2 inhibitors are currently available, they are more successful in laboratory research than in clinic. In addition to preventing interaction with p53, other methods of inhibiting MDM2 and MDMX include the inhibition of MDM2 E3 ligase activity or the MDM2-MDMX heterooligomerization. However, studies have suggested that the MDM2-MDMX RINGRING oligomer is not an attractive drug target due to the lack of a defined catalytic site and deep pocket for small compound insertion $[9,10]$. Drugs that can target MDM2 E3 ligase activity and simultaneously inhibit MDMX to maximize p53 stabilization and activation are clinically desirable.

Recent studies from our lab and others' have demonstrated that MDM2 and MDMX heterooligomerization through their RING domains is essential for p53 control, while the MDM2 E3 ligase function is dispensable for growth and development under unstressed conditions but becomes essential for survival after genotoxic stresses [11-13]. While the current models suggest that MDM2 and MDMX function through both independent and interdependent pathways to regulate $\mathrm{p} 53$, and both MDM2 and MDMX are essential 
in keeping p53 activities in check, these two homologues are also interact with and regulate one another. In vitro experiments have demonstrated a greater affinity for the formation of MDM2-MDMX heterooligomers than either MDM2 or MDMX homooligomers alone [14]. A proposed function for the MDM2-MDMX heterooligomer posits that it results in preferential degradation of MDMX and stabilization of MDM2 [15-17]. Studies have also shown that the MDM2-MDMX heterooligomer works as a better E3 ubiquitin ligase than MDM2 homooligomer alone, suggesting that MDMX facilitates MDM2 E3 function [18]. Consistent with this notion, ectopic overexpression of MDMX enhances MDM2 E3 ligase activity toward p53 [19] and rescues the activity of certain MDM2 mutants lacking E3 ligase activity [20]. However, despite intense research exactly how MDM2 and MDMX work individually and together to regulate p53 is still partially understood, and sometime striking differences can exist between in vitro and in vivo studies.

A major obstacle of investigating individual functions of MDM2 and MDMX in mice is the early embryonic lethality caused by inactivation of either one while in the presence of p53. To solve this problem we took advantage of a previously developed system [21], in which the p53 gene is replaced by one encoding a fusion protein containing a full-length p53 fused C-terminally with the hormone-binding domain of a modified estrogen receptor ( $\left.\mathrm{p} 53^{\mathrm{ER}}\right)$. The $p 53^{E R}$ gene is expressed at physiological levels under control of the native promoter [22]. The p53 $3^{\mathrm{ER}}$ activity can be rapidly switched between WT and knockout states by administration and withdrawal of 4-hydroxytamoxifen (4-OHT). We generated mice expressing inducible $p 53^{E R}$ under various MDM2 and MDMX deletion and mutation backgrounds and studied p53 regulation in mice and MEF cells. Unexpectedly, using the inducible $\mathrm{p} 53^{\mathrm{ER}}$ system we found that in vivo MDMX is essential for p53 degradation, as we found that in the presence of WT MDM2 and absence of MDMX the degradation of p53 is hardly detected [23]. Several possible mechanisms can be attributed to the role of MDMX in MDM2 degradation of p53. For example, we found that while in vivo MDM2 and MDMX can interact with p53 in the absence of each other, but they bind p53 more efficiently as a heterodimer; and that the MDM2-MDMX heterodimerization promotes p53 cytoplasmic localization, where p53 is degraded by the cytoplasmic proteasome. However, we believe the most likely mechanism for MDMX to enable MDM2 E3 ligase activity is its ability to bind $\mathrm{UbcH} 5 \mathrm{c}$ and bring it to MDM2 proximity. Previous studies have shown that knockdown UbcH5c in MCF-7 cells increases p53 expression [24], suggesting that $\mathrm{UbcH} 5 \mathrm{c}$ is a decisive ubiquitin-conjugating enzyme for p53 degradation. Using the inducible p53 ${ }^{\mathrm{ER}}$ system, we found that MDMX, but not MDM2, interacts with UbcH5c, and that the ability of MDMX to interact with both $\mathrm{UbcH} 5 \mathrm{c}$ and MDM2 is essential for MDM2 mediated p53 degradation [23]. We further demonstrated that the last seven residues of MDMX are required for $\mathrm{UbcH} 5 \mathrm{c}$ binding, and that replacing MDM2 C-terminal seven residues with the MDMX C-terminal seven residues enabled MDM2 to interact with $\mathrm{UbcH} 5 \mathrm{c}$ and enhanced MDM2 E3 ligase activity for p53 degradation in the absence of MDMX [23]. Based on this finding, targeting UbcH5c-MDMX binding should affect MDM2 E3 activity but not MDM2-MDMX interaction. Hence, in theory strategies or small molecule compounds that can disrupt UbcH5c-MDMX binding but not MDM2MDMX binding would stabilize p53 but not activate it, since the MDM2-MDMX heterooligomer can bind to and suppress the transcriptional function of p53 without necessarily degrade it. Such UbcH5c-MDMX bindingtargeting compounds can avoid exaggerated p53 activation caused by disrupting MDM2-p53 binding, but they may be used as p53 sensitizers in combination with chemo- and radio-therapeutics to activate $\mathrm{p} 53$ in a coordinated and controllable manner.

\section{CONFLICTS OF INTEREST}

Authors have no conflicts of interest to declare.

\section{REFERENCES}

1. Levine AJ, Feng Z, Mak TW, You H, Jin S. Coordination and communication between the 553 and IGF-1-AKT-TOR signal transduction pathways. Genes Dev. 2006; 20:267-75. https://doi.org/10.1101/gad.1363206. PMID:16452501

2. Vogelstein B, Lane D, Levine AJ. Surfing the p53 network. Nature. 2000; 408:307-10. https://doi. org/10.1038/35042675. PMID:11099028

3. Danovi D, Meulmeester E, Pasini D, Migliorini D, Capra M, Frenk R, de Graaf P, Francoz S, Gasparini P, Gobbi A, Helin K, Pelicci PG, Jochemsen AG, Marine JC. Amplification of Mdmx (or Mdm4) directly contributes to tumor formation by inhibiting p53 tumor suppressor activity. Mol Cell Biol. 2004; 24:5835-43. https://doi. org/10.1128/MCB.24.13.5835-5843.2004. PMID:15199139

4. Hainaut P, Soussi T, Shomer B, Hollstein M, Greenblatt M, Hovig E, Harris CC, Montesano R. Database of p53 gene somatic mutations in human tumors and cell lines: updated compilation and future prospects. Nucleic Acids Res. 1997; 25:151-57. https://doi.org/10.1093/nar/25.1.151. PMID:9016527

5. Momand J, Jung D, Wilczynski S, Niland J. The MDM2 gene amplification database. Nucleic Acids Res. 1998; 26:3453-59. $\quad$ https://doi.org/10.1093/nar/26.15.3453. PMID:9671804

6. Wade M, Li YC, Wahl GM. MDM2, MDMX and p53 in oncogenesis and cancer therapy. Nat Rev Cancer. 2013; 13:83-96. https://doi.org/10.1038/nrc3430. PMID:23303139 
7. Vassilev LT, Vu BT, Graves B, Carvajal D, Podlaski F, Filipovic Z, Kong N, Kammlott U, Lukacs C, Klein C, Fotouhi N, Liu EA. In vivo activation of the p53 pathway by small-molecule antagonists of MDM2. Science. 2004; 303:844-48. https://doi.org/10.1126/science.1092472. PMID:14704432

8. Ray-Coquard I, Blay JY, Italiano A, Le Cesne A, Penel N, Zhi J, Heil F, Rueger R, Graves B, Ding M, Geho D, Middleton SA, Vassilev LT, et al. Effect of the MDM2 antagonist RG7112 on the P53 pathway in patients with MDM2-amplified, well-differentiated or dedifferentiated liposarcoma: an exploratory proof-of-mechanism study. Lancet Oncol. 2012; 13:1133-40. https://doi.org/10.1016/ S1470-2045(12)70474-6. PMID:23084521

9. Kostic M, Matt T, Martinez-Yamout MA, Dyson HJ, Wright PE. Solution structure of the Hdm2 C2H2C4 RING, a domain critical for ubiquitination of p53. J Mol Biol. 2006; 363:433-50. https://doi.org/10.1016/j.jmb.2006.08.027. PMID:16965791

10. Linke K, Mace PD, Smith CA, Vaux DL, Silke J, Day CL. Structure of the MDM2/MDMX RING domain heterodimer reveals dimerization is required for their ubiquitylation in trans. Cell Death Differ. 2008; 15:841-48. https://doi. org/10.1038/sj.cdd.4402309. PMID:18219319

11. Itahana K, Mao H, Jin A, Itahana Y, Clegg HV, Lindström MS, Bhat KP, Godfrey VL, Evan GI, Zhang Y. Targeted inactivation of Mdm2 RING finger E3 ubiquitin ligase activity in the mouse reveals mechanistic insights into p53 regulation. Cancer Cell. 2007; 12:355-66. https://doi. org/10.1016/j.ccr.2007.09.007. PMID:17936560

12. Tollini LA, Jin A, Park J, Zhang Y. Regulation of $\mathrm{p} 53$ by Mdm2 E3 ligase function is dispensable in embryogenesis and development, but essential in response to DNA damage. Cancer Cell. 2014; 26:235-47. https://doi.org/10.1016/j. ccr.2014.06.006. PMID:25117711

13. Huang L, Yan Z, Liao X, Li Y, Yang J, Wang ZG, Zuo Y, Kawai H, Shadfan M, Ganapathy S, Yuan ZM. The p53 inhibitors MDM2/MDMX complex is required for control of p53 activity in vivo. Proc Natl Acad Sci U S A. 2011; 108:12001-06. https://doi.org/10.1073/pnas.1102309108. PMID:21730163

14. Gu J, Kawai H, Nie L, Kitao H, Wiederschain D, Jochemsen AG, Parant J, Lozano G, Yuan ZM. Mutual dependence of MDM2 and MDMX in their functional inactivation of p53. J Biol Chem. 2002; 277:19251-54. https://doi.org/10.1074/ jbc.C200150200. PMID:11953423

15. Pan Y, Chen J. MDM2 promotes ubiquitination and degradation of MDMX. Mol Cell Biol. 2003; 23:511321. https://doi.org/10.1128/MCB.23.15.5113-5121.2003. PMID:12860999
16. Kawai H, Wiederschain D, Kitao H, Stuart J, Tsai KK, Yuan ZM. DNA damage-induced MDMX degradation is mediated by MDM2. J Biol Chem. 2003; 278:45946-53. https://doi.org/10.1074/jbc.M308295200. PMID:12963717

17. de Graaf P, Little NA, Ramos YF, Meulmeester E, Letteboer SJ, Jochemsen AG. Hdmx protein stability is regulated by the ubiquitin ligase activity of Mdm2. J Biol Chem. 2003; 278:38315-24. https://doi.org/10.1074/jbc.M213034200. PMID:12874296

18. Linares LK, Hengstermann A, Ciechanover A, Müller S, Scheffner M. HdmX stimulates Hdm2-mediated ubiquitination and degradation of p53. Proc Natl Acad Sci U S A. 2003; 100:12009-14. https://doi.org/10.1073/ pnas.2030930100. PMID:14507994

19. Wang X, Wang J, Jiang X. MdmX protein is essential for $\mathrm{Mdm} 2$ protein-mediated p53 polyubiquitination. J Biol Chem. 2011; 286:23725-34. https://doi.org/10.1074/jbc. M110.213868. PMID:21572037

20. Uldrijan S, Pannekoek WJ, Vousden KH. An essential function of the extreme C-terminus of MDM2 can be provided by MDMX. EMBO J. 2007; 26:102-12. https:// doi.org/10.1038/sj.emboj.7601469. PMID:17159902

21. Christophorou MA, Martin-Zanca D, Soucek L, Lawlor ER, Brown-Swigart L, Verschuren EW, Evan GI. Temporal dissection of p53 function in vitro and in vivo. Nat Genet. 2005; 37:718-26. https://doi.org/10.1038/ng1572. PMID: 15924142

22. Martins CP, Brown-Swigart L, Evan GI. Modeling the therapeutic efficacy of p53 restoration in tumors. Cell. 2006; 127:1323-34. https://doi.org/10.1016/j.cell.2006.12.007. PMID:17182091

23. Yang J, Jin A, Han J, Chen X, Zheng J, Zhang Y. MDMX Recruits UbcH5c to Facilitate MDM2 E3 Ligase Activity and Subsequent p53 Degradation In Vivo. Cancer Res. 2021; 81:898-909. https://doi.org/10.1158/0008-5472. CAN-20-0790. PMID:33277368

24. Saville MK, Sparks A, Xirodimas DP, Wardrop J, Stevenson LF, Bourdon JC, Woods YL, Lane DP. Regulation of p53 by the ubiquitin-conjugating enzymes $\mathrm{UbcH} 5 \mathrm{~B} / \mathrm{C}$ in vivo. J Biol Chem. 2004; 279:42169-81. https://doi.org/10.1074/ jbc.M403362200. PMID:15280377 